\title{
Understanding Patients' Experiences of Treatment Burden in Chronic Heart Failure Using Normalization Process Theory
}

\author{
Katie Gallacher, $M B C b B, B S c$ \\ (MedSci), MRCGP, DFSRH ${ }^{1}$ \\ Carl R. May, PbD ${ }^{2}$ \\ Victor M. Montori, $M D^{3}$
}

Frances S. Mair, MD, DRCOG, FRCGP

'Academic Unit of General Practice and Primary Care, Centre for Population and Health Sciences, College of Medical, Veterinary and Life Sciences, University of Glasgow, Glasgow, Scotland

${ }^{2}$ Faculty of Health Sciences, Southampton University, Southampton, United Kingdom

${ }^{3}$ Knowledge and Encounter Research Unit, Mayo Clinic, Rochester, Minnesota

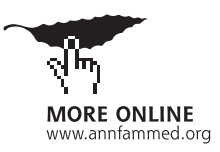

\begin{abstract}
PURPOSE Our goal was to assess the burden associated with treatment among patients living with chronic heart failure and to determine whether Normalization Process Theory (NPT) is a useful framework to help describe the components of treatment burden in these patients.
\end{abstract}

METHODS We performed a secondary analysis of qualitative interview data, using framework analysis, informed by NPT, to determine the components of patient "work." Participants were 47 patients with chronic heart failure managed in primary care in the United Kingdom who had participated in an earlier qualitative study about living with this condition. We identified and examined data that fell outside of the coding frame to determine if important concepts or ideas were being missed by using the chosen theoretical framework.

RESULTS We were able to identify and describe components of treatment burden as distinct from illness burden using the framework. Treatment burden in chronic heart failure includes the work of developing an understanding of treatments, interacting with others to organize care, attending appointments, taking medications, enacting lifestyle measures, and appraising treatments. Factors that patients reported as increasing treatment burden included too many medications and appointments, barriers to accessing services, fragmented and poorly organized care, lack of continuity, and inadequate communication between health professionals. Patient "work" that fell outside of the coding frame was exclusively emotional or spiritual in nature.

CONCLUSIONS We identified core components of treatment burden as reported by patients with chronic heart failure. The findings suggest that NPT is a theoretical framework that facilitates understanding of experiences of health care work at the individual, as well as the organizational, level. Although further exploration and patient endorsement are necessary, our findings lay the foundation for a new target for treatment and quality improvement efforts toward patientcentered care.

Ann Fam Med 2011;9:235-243. doi:10.1370/afm.1249.

\section{INTRODUCTION}

\section{CORRESPONDING AUTHOR}

Frances S. Mair, MD, DRCOG, FRCGP Academic Unit of General Practice and Primary Care

Centre for Population and Health Sciences

College of Medical, Veterinary and Life Sciences

University of Glasgow

1 Horselethill Rd

Glasgow, Scotland G12 9LX

Frances.Mair@glasgow.ac.uk

\footnotetext{
C hronic heart failure is an increasingly common, complex health problem that requires substantial personal investment from patients to manage disease demands. It is characterized by high levels of morbidity and mortality, and requires patients to follow complicated medication regimens and enact numerous lifestyle changes. ${ }^{1-5}$ This situation involves complex interactions between (1) factors related to health care professionals and systems, including organization and delivery of care, ${ }^{6}$ clinical superspecialization, and disease-centered approaches ${ }^{7} ;$ timetabling and resourcing of appointments, tests, and treatments ${ }^{8}$; and health care professionals' assumptions about patient expectations and behaviors ${ }^{9}$; and (2)
} 
factors related to patients' individual characteristics, ${ }_{1}^{10-12}$ the social and economic resources available to them, ${ }^{13,14}$ and their experiences of medical management, including appointments for evaluation or advice; enacting lifestyle changes and self-care; taking multiple medications; and living with therapeutic devices such as implantable cardioverter-defibrillators. ${ }^{1}$

In other words, chronic heart failure is an illness that places a great deal of work on the patient. It is likely that with continual advances in the field of medical science and technology, treatment regimens will become increasingly complex. Because of the demographic profile of people with chronic heart failure, this population often has comorbidities that will also have specific and sometimes demanding management plans, with limited coordination of care by health services exacerbating this workload. This situation creates a need for patientcentered rather than disease-centered services. ${ }^{7,15-17}$

Unsurprisingly, patients with chronic illness who perceive their management plans as more demanding are less likely to adhere to treatments. ${ }^{16,18}$ Nonadherence is a common problem for patients with chronic disease, with only $50 \%$ of them adhering to prescribed medication. ${ }^{14,19}$ Increasing treatment burden therefore has the potential to induce nonadherence, wasted resources, and poor outcomes, especially in those with complex comorbidities, ${ }^{15}$ thus making it an area worthy of further investigation.

Previous studies in this sphere have described the components of treatment burden in a limited way, for example, in relation to individual treatment adverse effects, ${ }^{20,21}$ or have included very small numbers of participants. $^{2}$ The research has therefore not provided a picture of the entire treatment burden experienced by patients, often excluding those with comorbidities, ${ }^{22}$ who represent almost one-half of all patients with chronic disease. ${ }^{16,23}$ Understanding the burden of treatment in this population is also important because patients with more than one condition to manage are at higher risk for preventable hospital admissions.

The aim of this study was to identify and understand the components of treatment burden in patients with chronic heart failure and comorbidity. A robust conceptualization of patient burden is needed in order to inform the development of tools to measure this burden and identify those most at risk.

To facilitate understanding of the components and dimensions of treatment burden, we used Normalization Process Theory (NPT). We hypothesized that this theory would be a useful conceptual tool because it provides a robust analytic framework for understanding the organization and operationalization of tasks (their implementation), of making them routine elements of daily life (their embedding), and of sustaining embedded practices in their social contexts (their integration). ${ }^{24} \mathrm{NPT}$ was developed through rigorous qualitative research ${ }^{24-26}$ and has been successfully used to understand the "work" involved in sickness careers. ${ }^{27}$ It explains how the work of enacting an ensemble of practices (here, the components of treatment burden) is accomplished through the operation of 4 mechanisms (Table 1): coherence (sense-making work), cognitive participation (relationship work), collective action (enacting work), and reflexive monitoring (appraisal work). ${ }^{24}$ We aimed to use NPT to identify, describe, and understand the components of treatment burden experienced by patients with chronic heart failure.

\section{METHODS}

We carried out qualitative analysis on archived interviews with patients having chronic heart failure

\section{Table 1. Normalization Process Theory Constructs}

\begin{tabular}{|c|c|c|c|}
\hline $\begin{array}{l}\text { Coherence } \\
\text { (Sense-Making Work) }^{a}\end{array}$ & $\begin{array}{l}\text { Cognitive Participation } \\
\text { (Relationship Work) }^{\mathrm{b}}\end{array}$ & $\begin{array}{l}\text { Collective Action } \\
\text { (Enacting Work)c }\end{array}$ & $\begin{array}{l}\text { Reflexive Monitoring } \\
\text { (Appraisal Work) }^{\mathrm{d}}\end{array}$ \\
\hline $\begin{array}{l}\text { Differentiation: } \\
\text { Defining, dividing up, and } \\
\text { categorizing task }\end{array}$ & $\begin{array}{l}\text { Enrollment: recruiting the self } \\
\text { and others to tasks }\end{array}$ & $\begin{array}{l}\text { Skill set workability: allocating } \\
\text { tasks and performances }\end{array}$ & Reconfiguration: changing tasks \\
\hline $\begin{array}{l}\text { Communal specification: mak- } \\
\text { ing sense of shared versions } \\
\text { of tasks }\end{array}$ & $\begin{array}{l}\text { Activation: organizing a shared } \\
\text { contribution to tasks }\end{array}$ & $\begin{array}{l}\text { Contextual integration: support- } \\
\text { ing and resourcing tasks in their } \\
\text { social contexts }\end{array}$ & $\begin{array}{l}\text { Communal appraisal: shared evalua- } \\
\text { tion of contributions and tasks }\end{array}$ \\
\hline $\begin{array}{l}\text { Individual specification: making } \\
\text { sense of personal versions } \\
\text { of tasks }\end{array}$ & $\begin{array}{l}\text { Initiation: organizing an indi- } \\
\text { vidual contribution to tasks }\end{array}$ & $\begin{array}{l}\text { Interactional workability: doing } \\
\text { tasks, and making outcomes, in } \\
\text { practice }\end{array}$ & $\begin{array}{l}\text { Individual appraisal: individual } \\
\text { evaluation of contributions and } \\
\text { tasks }\end{array}$ \\
\hline $\begin{array}{l}\text { Internalization: learning how to } \\
\text { do tasks in context }\end{array}$ & $\begin{array}{l}\text { Legitimation: making tasks the } \\
\text { right thing to do }\end{array}$ & $\begin{array}{l}\text { Relational integration: making } \\
\text { and communicating reliable } \\
\text { knowledge about tasks }\end{array}$ & $\begin{array}{l}\text { Systematization: organizing a reli- } \\
\text { able stock of knowledge about } \\
\text { tasks }\end{array}$ \\
\hline \multicolumn{4}{|c|}{$\begin{array}{l}\text { anvesting in making tasks meaningful. } \\
{ }^{b} \text { Investing personal and interpersonal commitment to tasks. } \\
\text { c Investing effort and resources in tasks. } \\
\text { d Investing in comprehending. }\end{array}$} \\
\hline
\end{tabular}




\begin{tabular}{|c|c|c|c|}
\hline $\begin{array}{l}\text { Coherence } \\
\text { (Sense-Making Work) }^{a}\end{array}$ & $\begin{array}{l}\text { Cognitive Participation } \\
\text { (Relationship Work) }^{\mathrm{b}}\end{array}$ & $\begin{array}{l}\text { Collective Action } \\
\text { (Enacting Work) }^{c}\end{array}$ & $\begin{array}{l}\text { Reflexive Monitoring } \\
\text { (Appraisal Work) }^{d}\end{array}$ \\
\hline $\begin{array}{l}\text { Differentiation: understanding and } \\
\text { differentiating between aspects } \\
\text { of the illness, tests, treatments, } \\
\text { and the roles of different health } \\
\text { professionals }\end{array}$ & $\begin{array}{l}\text { Enrollment: engaging with } \\
\text { friends, family, and health } \\
\text { professionals with regards } \\
\text { to the illness and its man- } \\
\text { agement to enable them to } \\
\text { provide support }\end{array}$ & $\begin{array}{l}\text { Skill set workability: setting a } \\
\text { routine/strategy to cope with } \\
\text { symptoms, exacerbations, and } \\
\text { emergency situations, that is } \\
\text { therapeutic interventions and } \\
\text { self-monitoring }\end{array}$ & $\begin{array}{l}\text { Reconfiguration: altering a } \\
\text { set routine when required, } \\
\text { such as medication regimens } \\
\text { or appointments, to fit in } \\
\text { with daily activities or other } \\
\text { arrangements }\end{array}$ \\
\hline $\begin{array}{l}\text { Communal specification: gaining } \\
\text { information about the illness and } \\
\text { its management with the help of } \\
\text { others, for example, friends, fam- } \\
\text { ily, or health professionals }\end{array}$ & $\begin{array}{l}\text { Activation: arranging help (eg, } \\
\text { logistical, administrative, or } \\
\text { expert) from health profes- } \\
\text { sionals, social services, or } \\
\text { friends and family }\end{array}$ & $\begin{array}{l}\text { Contextual integration: mak- } \\
\text { ing sure you have the right } \\
\text { financial and social resources, } \\
\text { and integrating the illness into } \\
\text { social circumstances }\end{array}$ & $\begin{array}{l}\text { Communal appraisal: discussing } \\
\text { or altering current management } \\
\text { plans already initiated, in dis- } \\
\text { cussion with health profession- } \\
\text { als or friends and family }\end{array}$ \\
\hline $\begin{array}{l}\text { Individual specification: achieving } \\
\text { your own understanding of the } \\
\text { illness and its management in } \\
\text { personal terms, through personal } \\
\text { research such as reading, or per- } \\
\text { sonal life experience }\end{array}$ & $\begin{array}{l}\text { Initiation: using organizational } \\
\text { skills to arrange one's own } \\
\text { contribution to manage- } \\
\text { ment, such as arranging pre- } \\
\text { scriptions, social care, and } \\
\text { transport to appointments }\end{array}$ & $\begin{array}{l}\text { Interactional workability: taking } \\
\text { treatments, enacting lifestyle } \\
\text { changes, attending appoint- } \\
\text { ments, enduring symptoms } \\
\text { and side effects }\end{array}$ & $\begin{array}{l}\text { Individual appraisal: assessing } \\
\text { individually whether to con- } \\
\text { tinue or alter current manage- } \\
\text { ment plans }\end{array}$ \\
\hline $\begin{array}{l}\text { Internalization: relating your } \\
\text { experience to the illness and its } \\
\text { treatment, understanding its } \\
\text { implications, knowing when to } \\
\text { seek help }\end{array}$ & $\begin{array}{l}\text { Legitimation: seeking reassur- } \\
\text { ance about treatments from } \\
\text { others about appropriate- } \\
\text { ness of management plans }\end{array}$ & $\begin{array}{l}\text { Relational integration: develop- } \\
\text { ing relationships with and con- } \\
\text { fidence in health professionals } \\
\text { and their interaction with each } \\
\text { other; overcoming barriers in } \\
\text { accessing care }\end{array}$ & $\begin{array}{l}\text { Systematization: developing ways } \\
\text { of keeping up to date with } \\
\text { newly available treatments }\end{array}$ \\
\hline
\end{tabular}

who lived in the United Kingdom and were being managed in primary care. These interviews were originally undertaken to explore patients' knowledge, understanding, and experiences of living with chronic heart failure and its management, including their information needs, the experience of the illness on their everyday lives and relationships, and the coping strategies adopted. ${ }^{28}$ The interviews were designed to gain insight into both the illness experience and the experience of disease management from the patient's perspective, and transcripts therefore contained data on treatment burden. A copy of the interview schedule is provided in Supplemental Appendix 1 (avail-

in able at http://www.annfammed.org/cgi/content/ full/9/3/235/DC1). In this reanalysis, we focused on what the data could tell us about the work of living with chronic heart failure and the treatment burdens that stem from it.

Participants were purposely sampled to ensure a wide range of ages as well as sex equality. Data consisted of interviews with 47 patients: 29 men and 18 women ranging in age from 45 to 88 years (mean age, 73 years). The sex distribution was even across the age categories. All patients had chronic heart failure confirmed by echocardiography and were receiving treatment with both angiotensin-converting enzyme inhibitors and diuretics from their family practitioner. The number of prescribed medications ranged from
4 to 13 (mean, 7), and the number of comorbidities ranged from 1 to 7 (mean, 3). The participants were, therefore, in these respects, typical of the population of chronic heart failure patients who are usually encountered in a primary care setting.

Interviews with these patients had been transcribed verbatim, and the transcripts were subjected to theoryled qualitative analysis. Two of the authors (K.G. and F.S.M.) drew on published work describing NPT ${ }^{24}$ to design a coding framework that accorded to the core constructs of the theory (Table 2) and illustrated how each of the components of treatment burden related to the NPT constructs. With this approach, we were able to operationalize the theory in a stable and consistent way, independently of the theory's developer (C.R.M).

We followed the 5 stages of framework analysis described by Ritchie and Lewis ${ }^{29,30}$ : familiarization, identifying a thematic framework, indexing, charting, and mapping and interpretation. Data on all health- and treatment-related issues, including comorbidities and their management, were coded. Because C.R.M. had led the development of the theory, 2 other authors (K.G. and F.S.M.) conducted primary coding of data; however, C.R.M. did adjudicate on disagreements about coding. The distribution of codes was recorded, and importantly, any data that fell outside of the coding frame were identified and examined to determine if important concepts or ideas were being missed by using 
the chosen theoretical framework. Additionally, because we used both archived data and framework methods, the iterative analysis of data normally undertaken in qualitative research was inappropriate.

We skeptically sought evidence for the adequacy of the NPT to help us define phenomena related to treatment burden, explain mechanisms, and make claims about treatment burden as a process. We therefore practically tested its usefulness as an analytic tool in the same way that other researchers have determined the usefulness of NPT for explaining processes at play in the implementation and integration of complex interventions. ${ }^{25}$ This process was essential to ensure that the analysis was not forced in any way and that it was equally possible for the coding frame to be assessed as inappropriate for categorizing the data as being affirmed as "fit for purpose."

We sought and obtained ethical approval from the Liverpool Ethics Committee. All participants gave their written informed consent.

\section{RESULTS}

\section{Components of Treatment Burden}

We identified 4 components of treatment burden, described below. A full taxonomy of treatment burden and examples of quotations from participants is shown

in Supplemental Table 1 (available at http://www. in annfammed.org/cgi/content/full/9/3/235/DC1), but Figure 1 summarizes the simple typology of treatment burden constructed from our findings. The main components (or themes) were learning about treatments and their consequences (sense-making work); engaging with others (participation work); adhering to treatments and lifestyle changes (enacting work, the most prominent theme); and monitoring treatments (appraisal work). These components are explained more fully below and are illustrated in the vignette constructed from the interview data (Figure 2).

\section{Learning About Treatments and Their}

\section{Consequences: Sense-making Work}

Learning about treatments and their consequences (effects) describes the work patients have to undertake to find out about and develop an understanding of treatments, various aspects of management, and their consequences. Patients frequently mentioned this theme, whereby they had to work to make coherent disparate understandings of their illness experience. For example, in relation to medications, they described having to learn names of tablets, understand why medications were being taken, and differentiate between different treatments. For example:

Well, I know they are water tablets, but I always thought that that was a heart tablet, but it's to do with the blood pressure.... It does strengthen the heart as well, but it's mostly for blood pressure (patient 24).

Patients also mentioned the work involved in understanding tests and their results. They were sometimes uncertain of why the tests had been done or what the results meant. Polypharmacy and having multiple tests increased the difficulty of achieving coherence.

Indeed, patients described challenges in obtaining information from others, such as health professionals, and described a range of activities they undertook, such as reading patient information leaflets, to address knowledge gaps. As one patient stated:

The only information that I get...is when you get these tablets in box form and they try and explain it to you. You get a bit more information that way than you would do in any other cases.... Reading the leaflet, the print is that small and they use very big words for the likes of me-it's foreign, I don't know what it means (patient 23). 
Another type of work mentioned was determining whether a treatment is working and knowing when to seek help. All of these activities required time and effort by participants.

\section{Engaging with Others/Mobilizing Resources: Participation Work}

Patients' engaging with others or mobilizing resources to help them with their required treatments encompassed a number of different activities. They frequently mentioned engaging with family members, for example, about their illness and its management, as well as having to arrange for others to provide practical support. Patients also spent time engaging with

\section{Figure 2. A vignette illustrating the components of treatment burden.}

Mr A, 58 years old, is a car mechanic who lives alone. He has recently been feeling tired and short of breath, but had put this down to "getting older." He wakes up one morning feeling extremely breathless, phones an ambulance, and is taken to hospital. He is admitted, investigated, and started on a range of therapies and told he has heart failure.

\section{GAINING AN UNDERSTANDING OF TREATMENTS}

Before being discharged home, Mr A is visited by a heart failure nurse, who says she will see him every month at the clinic, and that he will see the cardiologist once every 6 months. She gives him information leaflets on heart failure and arranges his first appointment. He is also visited by a dietician, who tells him to cut his fat and salt intake and gives him more leaflets to read.

\section{USING ORGANIZATIONAL SKILLS}

For the next few weeks Mr A finds that he is struggling to cope and arranges for his daughter to take him to his appointments at the hospital, but he has to cancel his first one as his daughter can't take him and he doesn't feel well enough to use public transport. He is offered another appointment the following week, but this is the same day as his appointment with the practice nurse for his annual CHD check up, so he arranges one for the week after that.

"I rang them to say I didn't feel able and I told them where I'd been and what had happened and they said that they would give me another appointment and that came this morning in the post."

\section{OVERCOMING ACCESS BARRIERS}

He tries to make an appointment with his family doctor on the same day he is seeing the practice nurse so that he can ask him some questions about his treatments, but he cannot get an appointment on the same day so will need to attend to practice twice.

"I thought I'm going to see $\operatorname{Dr} X$ and I couldn't get in so I thought I'd see Dr Y - I couldn't get in so that was on the Monday now the first appointment was for the Wednesday."

\section{TAKING MEDICATIONS}

Mr A also has to attend the practice every month to collect his prescription. He is now taking a total of 12 tablets a day, which he is struggling to finance because he is unable to work. He takes 6 tablets in the morning, 2 at lunchtime, 1 after dinner, and 3 at bedtime. Some of them need to be taken before food and some after, so he finds this difficult to plan. Sometimes he forgets to take them, so he has started a diary.

"I've got a book and I note everything down. I note down when I've taken it, the dose, I note the time, the drug and when I've taken it."

\section{ALTERING MANAGEMENT ROUTINES}

One of his medications is a water tablet, which he misses out if he has to go out of the house that day.

"If I'm going on a long trip on the bus well I never take one (furosemide) in the morning because you have to keep going to the toilet, so if I'm going a long way I miss the morning."

\section{APPRAISING TREATMENTS}

When he sees his family doctor, he asks him whether he thinks he should be taking all these tablets, as sometimes he worries that they interact and is not convinced that they help him. He has tried to read the leaflets that come with the medication, but the writing is too small. The doctor reassures him, and they decide together to cut the dose of his water tablet. His daughter has bought him a computer, and he regularly searches the Internet for information on his condition, but he continues to question whether his treatments are really necessary and is beginning to wonder whether all this effort is really worth it.
Time was also spent checking whether others, such as friends or family, thought that management plans were worthwhile and exploring what others thought of their progress or outlook. Patients also sometimes enlisted family members or friends to try to help them make sense of their treatments.

\section{Adhering to Treatments and Lifestyle Changes: Enacting Work}

The component of adhering to treatments and lifestyle changes describes the logistic, organizational, financial, and practical day-to-day activities patients have to undertake to adhere to treatments and recommended lifestyle changes, a major element of treatment burden that they commonly mentioned. This work included setting routines to cope with often complicated management plans. Patients frequently described a laborious regimen with many medications, often with troublesome adverse effects. It was clear that dealing with medication regimens and treatment adverse effects consumed vast amounts of time and energy. Patients reported that higher numbers of medications contributed to a greater burden, 
and found that using tools such as log books, records, and dosette boxes (pill organizers) helped them to follow their regimens more accurately, as one patient stated:

I've got a book and I note everything down. I note down when I've taken it, the dose, I note the time, the drug, and when I've taken it (patient 10).

Much effort was also expended on the financial consequences of chronic illness and trying to adapt daily activities and home circumstances to accommodate life with a chronic condition. Patients reported the considerable work of attending appointments, with multiple visits to the hospital for tests and clinic appointments, recurrent admissions, and frequent visits to their family practitioner. This burden was worsened by poor communication at the primary-secondary care interface, as patients had to make numerous appointments with family practitioners until contact had finally been made with their specialist, enabling management plans to be altered.

Patients also described difficulties accessing a range of services, including health and social services; trouble accessing social services sometimes exacerbated the problems individuals encountered in integrating their illness and its management into their social circumstances. Both reception staff and health professionals were often perceived as too busy to help.

Additionally, poor coordination and lack of continuity of care was a recurring theme that made it more difficult for patients to develop effective therapeutic relationships and adversely affected levels of confidence in professionals and management plans, as this patient described:

The thing is, it's wasting my time asking any doctor in the practice because they don't know. It's because I see Dr X and she says that she's had nothing from the hospital for months. I'm going down to see a specialist all the time, but it's just that they are slack in telling my doctor...there is definitely a breakdown in paperwork (patient 8).

\section{Monitoring the Treatments: Appraisal Work}

Monitoring treatments describes the work patients undertook to continuously track their treatments and adjust them if necessary. Patients described independently reviewing and altering medication regimens to fit in with their planned schedule of activities on a dayto-day basis, particularly altering the timing of taking certain medications such as diuretics. For example, one patient stated the following:

If I'm going on a long trip on the bus, well I never take one (furosemide) in the morning because you have to keep going to the toilet, so if I'm going a long way, I miss the morning (patient 33).
Patients also reviewed and amended other aspects of their condition management, for instance, in relation to lifestyle advice relating to diet or exercise. Much time was spent assessing management plans either with the help of others (mainly medical staff) or alone. Only a single patient mentioned keeping up to date with new treatments.

\section{Data Outside the Coding Framework}

A small proportion of data fell outside our coding framework. These data either (1) were not related to the health of the individual or their treatments, or (2) focused on beliefs/attitudes or emotions (eg, spirituality or feelings about death) rather than on the burden of treatment. The following quotation exemplifies data of this nature:

The only thing I dread is being in a nursing home or something like that. I only hope that when my active life comes to an end that the Lord will take me home and I'll go to heaven (patient 38).

\section{DISCUSSION}

Our study shows the wide range and substantial burden of "work" patients with chronic heart failure need to undertake to manage their disease, a largely unexplored subject.

Coherence, the work of understanding treatments and tests, was a clear challenge for participants. A substantial existing body of research demonstrates that improving understanding by enhancing access to information and improving the patient-health professional consultation can increase medication adherence. ${ }^{31}$ The idea that patients must work to achieve coherence of disparate understandings of their illness experience and facts about treatment is a critical and largely unarticulated idea, however. These findings underscore the importance of ensuring adequate access to information and good communication between patients and health professionals.

Management of chronic illness currently tends to be disease centered rather than patient centered, with each patient attending multiple primary and secondary care appointments on different days for various clinical needs. The adverse effects on treatment burden for the individual may contribute to the high nonattendance rates at so many hospital and primary care appointments ${ }^{32-34}$ as patients become overwhelmed with appointments to organize and transportation to arrange. It is possible to arrange the workup and management of chronic conditions more efficiently, so that multiple tests can be conducted and results obtained in a single visit, or different appointments can be arranged for the same day, in both primary and 
secondary care. Precedents for this exist, for example, so-called one-stop heart failure services, which enable patients to go to the hospital for a comprehensive assessment involving blood tests, electrocardiogram, echocardiography, and access to a consultant cardiologist. Such methods of service provision have been adopted in a number of clinical areas and could be extended. As well as improving coordination of care, promoting bidirectional flow of information electronically between primary and secondary care services could reduce the burden for patients caused by current inefficiencies in the system.

Polypharmacy and frequent alterations of medications present a challenge to patients with chronic heart failure. Participants emphasized the importance of tools such as log books and dosette boxes to aid medication adherence, thus demonstrating the importance of ensuring the widest possible availability of such tools to minimize treatment burden. It is possible to reduce the burden of taking multiple medications by altering medication regimens to ensure the least number of tablets or dosing times; however, the conflict between cost and convenience for patients requires consideration.

For example, it may be cheaper to prescribe 2 tablets at one-half the dosage rather than 1 tablet of the full dosage. These difficult prescribing decisions must be made on a case-by-case basis and, in the United States, are likely to depend on a patient's financial circumstances and insurance arrangements. The use of so-called polypills, which combine multiple drugs in a single pill, is an innovative but controversial idea that has recently received attention in medical research. ${ }^{35}$ There has been skepticism about efficacy and adverse effects of such medication, but this is certainly an interesting area that requires further investigation, as a polypill has the potential to reduce treatment burden for patients. ${ }^{36}$

Lastly, and importantly, continuity of care was clearly key to participants, a factor likely to be more important to those with chronic rather than acute illness, and one that policy makers and practitioners must consider. An excellent example underscoring the need for continuity is that participants described frequent alterations to medication as a result of a lack of continuity of care, and again, a more coordinated, patientcentered service would ease this burden for patients.

It is noteworthy that very few treatment burden data fell outside our NPT coding frame, and any that did consisted of emotional work, for example, spiritual thoughts or anxieties about death. Certain aspects of emotional work, such as forming personal beliefs about treatments, reflecting on management plans, dealing with symptoms of depression, and developing confidence in health professionals, can be identified by our coding frame. We conclude, however, that some aspects of emotional work are not assessable in their entirety by NPT, and because emotional burden is an important aspect of living with chronic heart failure demanding comprehensive assessment, it is better addressed using other measures. Numerous quality of life instruments are available for assessing patients with chronic heart failure, many of which cover aspects of emotional burden. ${ }^{37-39}$ Whether these measures provide a comprehensive assessment of emotional work requires further research, and this important aspect of living with chronic illness must not be overlooked.

This study had limitations in that it involved a secondary analysis of previously collected qualitative data that was not originally intended to explore the issue of treatment burden, but rather to explore patient perceptions of the challenges they faced in living with heart failure and their knowledge and understanding of their illness. It is therefore possible that not all aspects of treatment burden have been identified, and it will be important to undertake collection of prospective qualitative data that is focused entirely on this issue to verify these results. Second, this is a qualitative study that identifies areas of treatment burden, but does not provide information about the relative importance of the components of this burden. Also, the interviews were conducted with patients from the United King$\mathrm{dom}_{\text {; }}$ therefore, our knowledge of treatment burden is limited to this patient group. There are likely to be many similarities between patient work in the United Kingdom and other westernized countries, such as the United States, but there will also be differences worthy of exploration. For example, differences in health care systems create different burdens, with negotiating with insurers and financial constraints being a major consideration for US patients when managing chronic illness. Finally, ours was an entirely novel use of NPT. Although this theory appears to offer a robust conceptual framework for understanding the burden of treatment, further work is needed to substantiate and develop it as a means of understanding burden of treatment in chronic illness.

Our study also had noteworthy strengths. They include the large number of patient interviews analyzed, as well as the robust approach to analysis, using a clear theoretical framework, conducted by 2 parties independently, with comparison of results and discussion of any differences with a third party. Furthermore, the approach taken allowed critical appraisal of the utility of NPT as a theory to aid conceptualization of the problem of treatment burden.

In conclusion, this study has identified key components of treatment burden experienced by patients with chronic heart failure and comorbidities. Although further exploration and patient endorsement are nec- 
essary, our findings lay the foundation for a new target for treatment and quality improvement efforts toward patient-centered care. This study also suggests that NPT is a useful theoretical framework for understanding patients' experiences of illness and health care services, and their active contributions to their overall care and self-care.

\section{To read or post commentaries in response to this article, see it} online at http://www.annfammed.org/cgi/content/full/9/3/235.

Key words: Chronic heart failure; comorbidity; treatment burden; burden of illness; Normalization Process Theory; treatment work; patient experience

Submitted June 29, 2010; submitted, revised, December 3, 2010; accepted December 15, 2010.

This work was previously presented in part at the ADEGS conference (Departments of Primary Care in Aberdeen, Dundee, Edinburgh, Glasgow, St Andrews), January 2010, Dundee, Scotland; the Scottish School of Primary Care Conference, April 2010, Crieff, Scotland; the British Cardiovascular Society Conference, June 2010, Manchester, England; the Society for Academic Primary Care Conference, July 2010, Norwich, England; and the North American Primary Care Research Group Conference, November 2010, Seattle, Washington.

Funding support: This study was funded by the Chief Scientist Office (CSO) Scotland, grant CZG/3/22. The authors have support from the University of Glasgow for the submitted work.

Disclaimer: All researchers involved are completely independent of the funder. The study sponsor(s) or funder(s) had no role in study design; in the collection, analysis, and interpretation of data; in the writing of the report; and in the decision to submit the article for publication. The authors have no relationships with the University of Glasgow that might have an interest in the submitted work in the previous 3 years. All authors, external and internal, had full access to all of the data (including statistical reports and tables) in the study and can take responsibility for the integrity of the data and the accuracy of the data analysis.

Acknowledgments: We would like to thank Jane Goodfellow for her contribution to the design of Figures 1 and 2, and Dr Ffion LloydWilliams who undertook the original interviews. The authors are part of a collaborative research group interested in minimally disruptive medicine. The group is carrying out a series of projects aimed at understanding treatment burden in chronic disease with the goal of creating a measurement tool.

\section{References}

1. Cowie MR, Zaphiriou A. Management of chronic heart failure. BMJ. 2002;325(7361):422-425.

2. Granger BB, Sandelowski M, Tahshjain H, Swedberg K, Ekman I. A qualitative descriptive study of the work of adherence to a chronic heart failure regimen: patient and physician perspectives. J Cardiovasc Nurs. 2009;24(4):308-315.

3. Schocken DD, Arrieta MI, Leaverton PE, Ross EA. Prevalence and mortality rate of congestive heart failure in the United States. J Am Coll Cardiol. 1992;20(2):301-306.

4. Welstand J, Carson A, Rutherford P. Living with heart failure: an integrative review. Int J Nurs Stud. 2009;46(10):1374-1385.
5. McMurray JJ, Stewart S. Epidemiology, aetiology, and prognosis of heart failure. Heart. 2000;83(5):596-602.

6. Wagner EH. Chronic disease management: what will it take to improve care for chronic illness? Eff Clin Pract. 1998;1(1):2-4.

7. Stange KC. The generalist approach. Ann Fam Med. 2009; 7(3):198-203.

8. May C. Mundane medicine, therapeutic relationships, and the clinical encounter: current and future agendas for sociology. In: Scambler G, Scambler S, eds. Assaults on the Lifeworld: New Directions in the Sociology of Chronic and Disabling Conditions. London, England: Routledge; 2010.

9. Hart E. System induced setbacks in stroke recovery. Sociol Health Illn. 2001;23(1):101-123.

10. Bane C, Hughes CM, McElnay JC. Determinants of medication adherence in hypertensive patients: an application of selfefficacy and the Theory of Planned Behaviour. Int J Pharm Pract. 2006;14(3):197-204

11. Buetow S, Elwyn G. Patient safety and patient error. Lancet. 2007; 369(9556):158-161.

12. Buetow S, Kiata L, Liew T, Kenealy T, Dovey S, Elwyn G. Patient error: a preliminary taxonomy. Ann Fam Med. 2009;7(3):223-231.

13. Barber N, Parsons J, Clifford S, Darracott R, Horne R. Patients' problems with new medication for chronic conditions. Qual Saf Health Care. 2004;13(3):172-175.

14. World Health Organization. Adherence to long-term therapiesevidence for action. 2003. http://apps.who.int/medicinedocs/en/d/ Js4883e/5.html. Accessed April 19, 2011.

15. May C, Montori VM, Mair FS. We need minimally disruptive medicine. BMJ. 2009;339:b2803.

16. Bayliss EA, Steiner JF, Crane LA, Main DS. Descriptions of barriers to self-care by persons with comorbid chronic diseases. Ann Fam Med. 2003;1(1):15-21.

17. Institutes of Medicine. Committee on Quality of Health Care in America. Crossing the Quality Chasm: A New Health System for the 21st Century. Hyattsville, MD: IOM; 2001.

18. Vijan S, Hayward RA, Ronis DL, Hofer TP. Brief report: the burden of diabetes therapy: implications for the design of effective patientcentered treatment regimens. J Gen Intern Med. 2005;20(5): 479-482.

19. Haynes RB, McDonald HP, Garg AX. Helping patients follow prescribed treatment: clinical applications. JAMA. 2002;288(22): 2880-2883.

20. Henry DH, Viswanathan HN, Elkin EP, Traina S, Wade S, Cella D. Symptoms and treatment burden associated with cancer treatment: results from a cross-sectional national survey in the U.S. Support Care Cancer. 2008;16(7):791-801.

21. Monahan PO, Lane KA, Hayes RP, McHorney CA, Marrero DG Reliability and validity of an instrument for assessing patients' perceptions about medications for diabetes: the PAM-D. Qual Life Res. 2009;18(7):941-952.

22. Clark NM, Becker MH, Janz NK, Lorig K, Rakowski W, Anderson L. Self-management of chronic disease by older adults: a review and questions for research. J Aging Health. 1991;3(1):3-27.

23. Hoffman C, Rice D, Sung HY. Persons with chronic conditions. Their prevalence and costs. JAMA. 1996;276(18):1473-1479.

24. May C, Finch T. Implementing, embedding, and integrating practices: an outline of Normalization Process Theory. Sociology. 2009;43(3):535-554.

25. May CR, Mair F, Finch T, et al. Development of a theory of implementation and integration: Normalization Process Theory. Implement Sci. 2009;4(29):29.

26. Normalization Process Theory [Web site]. 2010. http://www.normalizationprocess.org/bibliography.aspx. Accessed April 19, 2011. 
27. May C. Retheorizing the clinical encounter. In: Scambler G, Scambler S, eds. Assaults on the Lifeworld: New Directions in the Sociology of Chronic and Disabling Conditions. London, England: Routledge; 2010.

28. Mair F. Chronic Heart Failure: From Epidemiology to Experience. Liverpool, United Kingdom: Faculty of Medicine, University of Liverpool; 2004

29. Ritchie J, Lewis J. Qualitative Research Practice: A Guide for Social Science Students and Researchers. London, England: Sage Publications; 2003.

30. Pope C, Ziebland S, Mays N. Qualitative research in health care. Analysing qualitative data. BMJ. 2000;320(7227):114-116.

31. Golin CE, DiMatteo MR, Gelberg L. The role of patient participation in the doctor visit. Implications for adherence to diabetes care. Diabetes Care. 1996;19(10):1153-1164

32. NHS. The Information Centre. New statistics on outpatients' care confirm millions of missed appointments. 2007. http://www.ic.nhs. uk/news-and-events/press-office/press-releases/archived-pressreleases/april-2006--march-2007/new-statistics-on-outpatients-careconfirm-millions-of-missed-appointments. Accessed April 19, 2011.
33. Stone CA, Palmer JH, Saxby PJ, Devaraj VS. Reducing non-attendance at outpatient clinics. J R Soc Med. 1999;92(3):114-118.

34. Dockery F, Rajkumar C, Chapman C, Bulpitt C, Nicholl C. The effect of reminder calls in reducing non-attendance rates at care of the elderly clinics. Postgrad Med J. 2001;77(903):37-39.

35. Cannon CP. Can the polypill save the world from heart disease? Lancet. 2009;373(9672):1313-1314.

36. Yusuf $\mathrm{S}$. Two decades of progress in preventing vascular disease Lancet. 2002;360(9326):2-3.

37. Tate CW III, Robertson AD, Zolty R, et al. Quality of life and prognosis in heart failure: results of the Beta-Blocker Evaluation of Survival Trial (BEST). J Card Fail. 2007;13(9):732-737.

38. Sneed NV, Paul S, Michel Y, Vanbakel A, Hendrix G. Evaluation of 3 quality of life measurement tools in patients with chronic heart failure. Heart Lung. 2001;30(5):332-340.

39. Johansson P, Agnebrink M, Dahlström U, Broström A. Measurement of health-related quality of life in chronic heart failure, from a nursing perspective-a review of the literature. Eur J Cardiovasc Nurs. 2004;3(1):7-20

Please complete this form and mail to the following address or fax to Annals Circulation at 913-906-6080:

Annals of Family Medicine, Circulation Department, 11400 Tomahawk Creek Pkwy, Leawood, KS 66211-2680

Check if member of sponsoring organization: $\square$ AAFP $\square$ ABFM $\square$ STFM $\square$ ADFM

$\square$ AFMRD $\square$ NAPCRG $\square$ CFPC

ID number from label on your journal cover

OLD Information (Please print.)

\section{Name}

Company (if applicable)

Address (Street plus Apt or Ste)

City

Country

Telephone

E-Mail
NEW Information (Please print.)

\begin{tabular}{ll}
\hline Name & \\
\hline Company (if applicable) & \\
\hline Address (Street plus Apt or Ste) & State \\
\hline City & Postal Code (9-digit ZIP for US) \\
\hline Telephone & Fax \\
\hline E-Mail &
\end{tabular}

